\title{
Induction of Systemic Resistance against Cucumber mosaic virus in Arabidopsis thaliana by Trichoderma asperellum SKT-1
}

\author{
Mohsen Mohamed Elsharkawy ${ }^{1}$, Masafumi Shimizu ${ }^{4}$, Hideki Takahashi ${ }^{2}$, Kouichi Ozaki ${ }^{3}$ and \\ Mitsuro Hyakumachi* ${ }^{*}$ \\ ${ }^{1}$ United Graduate School of Agriculture Science, Gifu University, Gifu City 501-1193, Japan \\ Department of Agricultural Botany, Faculty of Agriculture, Kafr El-Sheikh University, 33516, Egypt \\ ${ }^{2}$ Department of Life Science, Graduate School of Agricultural Science, Tohoku University, Sendai 981-8555, Japan \\ ${ }^{3}$ Life Science Research Institute, Kumiai Chemical Industry Co., Ltd, Kikugawa, Shizuoka, Japan \\ ${ }^{4}$ Laboratory of Plant Pathology, Faculty of Applied Biological Sciences, Gifu University, Gifu City 501-1193, Japan \\ (Received on July 26, 2012; Revised on January 22, 2013; Accepted on January 22, 2013)
}

Trichoderma asperellum SKT-1 is a microbial pesticide that is very effective against various diseases. Our study was undertaken to evaluate $T$. asperellum SKT-1 for induction of resistance against yellow strain of Cucumber mosaic virus (CMV-Y) in Arabidopsis plants. Disease severity was rated at 2 weeks post inoculation (WPI). CMV titre in Arabidopsis leaves was determined by indirect enzyme-linked immunosorbent assay (ELISA) at 2 WPI. Our results demonstrated that among all $\mathrm{Arabi}$ dopsis plants treated with barley grain inoculum (BGI) of SKT-1 NahG and nprl plants showed no significant reduction in disease severity and CMV titre as compared with control plants. In contrast, disease severity and CMV titre were significantly reduced in all Arabidopsis plants treated with culture filtrate (CF) of SKT-1 as compared with control plants. RT-PCR results showed increased expression levels of SA-inducible genes, but not JA/ET-inducible genes, in leaves of BGI treated plants. Moreover, expression levels of SA- and JA/ETinducible genes were increased in leaves of $\mathrm{CF}$ treated plants. In conclusion, BGI treatment induced systemic resistance against CMV through SA signaling cascade in Arabidopsis plants. While, treatment with CF of SKT1 mediated the expression of a majority of the various pathogen related genes, which led to the increased defense mechanism against CMV infection.

Keywords : Arabidopsis thaliana, Cucumber mosaic virus, Induced systemic resistance, signaling pathway, Trichoderma asperellum SKT-1

Cucumber mosaic virus (CMV) is one of the most widespread and harmful plant viruses, infecting more than 1200

\footnotetext{
*Corresponding author.

Phone) +81-58-293-2847, FAX) +81-58-293-2847

E-mail)hyakumac@cc.gifu-u.ac.jp
}

plant species worldwide and it is efficiently transmitted by more than 80 aphid species (Dubey et al., 2010; Palukaitis and Garcia-Arenal, 2003). Because CMV depends on the plant host for survival, it is difficult to eliminate it without damaging the host plant.

Resistance in plants to pathogens can be induced by treatment with biotic and a biotic elicitors (Beauchamp et al., 2002; Beck et al., 1996; Bellamy et al., 1995; Lawton et al., 1996; van Loon et al., 1998). Recently, Ryu et al. (2004) reported the plant growth promoting rehizobacteria-mediated protection against CMV in A. thaliana. Additionally, tobacco plants treated with a Bacillus sp. showed increased resistance against CMV (Wang et al., 2009).

Salicylic acid (SA), jasmonates (JA) and ethylene (ET) are well known to play crucial roles in plant disease and pest resistance (Robert-Seilaniantz et al., 2007). Induced resistance responses in plants can be subdivided to two categories, systemic acquired resistance (SAR) and induced systemic resistance (ISR). SAR is associated with both local and systemic increase of SA levels, and the expression of pathogensis-related genes is mediated via SA pathway (Malamy et al., 1990; Ryals et al., 1996). While, ISR of plants against pathogens is a widespread phenomenon that has been intensively investigated with respect to the underlying signaling pathways as well as to its potential use in plant protection (Heil and Bostock, 2002). Unlike SAR, ISR is independent of the accumulation of SA or pathogensis related proteins (Pieterse et al., 1996), but instead, depends on pathways regulated by JA and ET (Knoester et al., 1999; Pieterse et al., 1996; Yan et al., 2002). Recently, however in some cases, the evidence indicating partial involvement of SA-dependent signaling pathway was presented (Elsharkawy et al., 2012a). Both SAR and ISR are effective against a broad spectrum of pathogens (van Loon et al., 1998; Durrant and Dong, 2004). Activation of ISR is associated with rapid and strong expression of plant 
defense genes (priming) after pathogen attack (Conrath et al., 2006). Pathogenesis-related proteins (PRs) are produced in plants in response to infection by virus, bacteria, fungi and viroids (Conejero et al., 1979; Gianinazi et al., 1980; Metraux and Boller, 1986). Most PRs and related proteins are induced through the action of the signaling compounds salicylic acid, jasmonic acid, or ethylene, and possess antimicrobial activities in vitro through hydrolytic activities on cell walls, contact toxicity, and perhaps an involvement in defense signaling (van Loon et al., 2006). Recent study has demonstrated that $T$. asperellum SKT-1 treated plants increased the expression levels of PR genes, which resulted in resistance to the leaf pathogens (Yoshioka et al., 2011).

Trichoderma species are naturally occurring soil fungi that colonize a wide range of plant roots. Trichoderma comprises of a heterogeneous group of fungi that act as biological control agents against wide spectrum of plant pathogens. The antagonistic properties of these fungi are based on the activation of multiple mechanisms including, faster metabolic rates, cell wall degrading enzymes and anti-fungal metabolites. Trichoderma species showed a widespread capacity to induce systemic resistance against various classes of plant pathogens including fungi, bacteria and viruses in a variety of plants (Harman et al., 2004). Among various species of Trichoderma, T. asperellum SKT-1 is a microbial pesticide isolated from Japanese turf grass (Zoysia japonica). SKT-1 was found to be highly effective against four diseases of rice caused by seedborne pathogens: Bakanae disease caused by Gibberella fuikuroi, bacterial seedling blight caused by Burkholderia plantarii, bacterial grain rot caused by Burkholderia glumae, and bacterial brown stripe caused by Acidovorax spp. (Kumakura et al., 2003). Additionally, root colonization by $T$. asperellum has been recently shown to be effective against different types of pathogens in a wide variety of plants, including Arabidopsis. For example, both barley grain inoculums (BGI) and culture filtrate (CF) from $T$. asperellum SKT-1 has been shown to induce systemic resistance against the foliar bacterial pathogen Pseudomonas syringae pv. tomato (Pst) in Arabidopsis plants (Yoshioka et al., 2011). Culture filtrates from other non-pathogenic microorganisms have also been shown to activate host resistance in many different plant species when they are applied to their leaves or roots (Hossain et al., 2007; Meera et al., 1994; Koike et al., 2001).

In this study, we tested the ability of SKT-1 to induce systemic resistance against CMV infection in Arabidopsis plants. We also investigated what types of signaling pathways were involved in ISR by SKT-1.

\section{Materials and Methods}

Plants, fungi and pathogens. T. asperellum SKT-1 (FERMP-
16 510; International Patent Organism Depositary, Ibaraki, Japan) was used in this study. K. S. Park (NIAST, Suwon, Korea) provided the seeds for the Arabidopsis thaliana L. ecotype Columbia (Col-0). The mutants, ein3 (Chao et al., 1997), jarl (Staswick et al., 1992) and nprl (Cao et al., 1994), were obtained from the Nottingham Arabidopsis Stock Centre. The transgenic line NahG (Lawton et al., 1995) was a personal gift. All mutants and transgenic Arabidopsis were generated in a Col-0 background. The yellow strain of Cucumber mosaic virus (CMV-Y) was obtained from the Laboratory of Plant Pathology, Tohoku University, Japan. The virus was maintained in tobacco plants (Nicotiana tabacum cv. Xanthi-nc).

Barley grain inoculum (BGI). Autoclaved barley grains (100 $\mathrm{g}$ in $100 \mathrm{ml}$ water) were inoculated in a $500 \mathrm{ml}$ Erlenmeyer flask with 10-15 disks ( $5 \mathrm{~mm}$ ) obtained from the actively growing margin of 7 days old potato dextrose agar (PDA; $2 \%$ agar) cultures of T. asperellum SKT-1. After 2 weeks of incubation at $25^{\circ} \mathrm{C}$ in the dark, the completely colonised barley grains were air-dried at room temperature $\left(23-25^{\circ} \mathrm{C}\right)$. The dried BGI was ground to a $1-2 \mathrm{~mm}$ particle size and stored at $4^{\circ} \mathrm{C}$ until further use.

Cell-free culture filtrate (CF). $T$. asperellum SKT-1 was cultured in PDA medium for 7 days. Twenty mycelial disks ( $5 \mathrm{~mm}$ ) of T. asperellum SKT-1 culture were obtained from the growing margin of a colony and transferred to a $500 \mathrm{ml}$ Erlenmeyer flask containing $200 \mathrm{ml}$ potato dextrose broth (PDB). The fungus was cultured without shaking at room temperature $\left(25^{\circ} \mathrm{C}\right)$ for 10 days. The crude culture filtrate was separated from the mycelia and filtered through two layers of Whatman No. 2 filter paper. The filtrate was then filter sterilised $(0.22 \mu \mathrm{m}$ Millipore filters, Millipore products division, Bedford, USA).

Cultivation of plants in soil. Arabidopsis seeds were sterilised by immersion in $70 \%$ ethanol for $2 \mathrm{~min}$ followed by $2 \%(\mathrm{v} / \mathrm{v}) \mathrm{NaOCl}$ for $2 \mathrm{~min}$, thoroughly rinsed three times in sterile distilled water, and vernalised for 2 days at $4^{\circ} \mathrm{C}$ in the absence of light. The seeds were soaked in 0.5 $\mathrm{ml}$ of distilled water in eppendorf tubes and stored in a refrigerator for 3 days at $4^{\circ} \mathrm{C}$ to synchronise germination. Sterilised pots were filled with approximately $100 \mathrm{~g}$ of autoclaved commercial potting medium "Star-bed" (soil-less, peat-based potting medium, which contains humus, rock phosphate and composted plant materials, Kyodohiryo Co. Ltd., Aichi, Japan) and transplanted with Arabidopsis plants. The plants were cultivated in a growth chamber under a 9/ 15-h day/night cycle at $22^{\circ} \mathrm{C}$ for 3 weeks.

Cultivation of plants in rock-wool. Arabidopsis seeds 
were sterilized as described previously. Using sterilised rock wool, five seeds were individually sown in each cube of rock wool, and only one plant was allowed to grow after germination. The plants were irrigated with MGRL nutrient solution at a concentration of $10^{-1}$ (Fujiwara et al., 1992) once a week and kept in the growth chambers at the growth conditions described previously.

Fungal and chemical pre-treatment. Autoclaved potting medium in sterile pots was amended with the powdered BGI $(0.5 \% \mathrm{w} / \mathrm{w})$ of $T$. asperelllum SKT-1 and transplanted with three weeks old Arabidopsis seedlings. Autoclaved potting medium supplemented with an equal volume of autoclaved barley grain served as a control. In case of rock wool-grown plants, induction treatment was performed $1 \mathrm{~d}$ before challenge inoculation by dipping the roots of 4 weeks old Arabidopsis plants in 50\% diluted CF T. asperelllum SKT-1 with distilled water for $1 \mathrm{~h}$, and subsequently, the excess $\mathrm{CF}$ was washed away with distilled water. The control plants were treated with 50\% diluted PDB.

Root colonisation. The root colonisation of T. asperelllum SKT-1 was evaluated in Arabidopsis plants three weeks after the treatment application. The roots were collected from nine randomly selected plants, washed with tap water to remove the adhering soil, rinsed three times with steriledistilled water and blotted to dryness. Subsequently, the roots were cut into 1-cm segments, plated in PDA amended with $200 \mathrm{mg} \mathrm{l}^{-1}$ of chloramphenicol and incubated for 3-4 days at $25^{\circ} \mathrm{C}$. After incubation, the T. asperelllum SKT-1 colonies were identified by the colour and growth pattern of the mycelia and pigments produced. The isolation frequency of the fungus was determined by counting the number of colony-forming root segments among the 100 root segments plated per replicate as described by Meera et al. (1995).

Cucumber mosaic virus inoculations. The virus was maintained in tobacco plants (Nicotiana tabacum cv. Xanthi-nc). The CMV inoculum used throughout the experiments consisted of infected tobacco leaf tissue ground in $0.01 \mathrm{M}$ sodium phosphate buffer, $\mathrm{pH}$ 7.0, containing $0.002 \mathrm{M}$ EDTA ( $1 \mathrm{~g}$ tissue per $50 \mathrm{ml}$ sodium phosphate buffer). All inoculation materials were chilled at $4{ }^{\circ} \mathrm{C}$ prior to the inoculation and maintained on ice during the inoculation. The plants were inoculated at 4 weeks after planting by rub inoculation onto the oldest leaf.

Enzyme-linked immunosorbent assay (ELISA). Indirect enzyme-linked immunosorbent assay (ELISA), as described previously (Zehnder et al., 2000) with some modifications, was used to determine the CMV-Y concentration. The leaf samples were collected at 14 DPI. The leaf samples were ground in $50 \mathrm{mM}$ carbonate buffer $(\mathrm{pH}$ 9.6) and added to microtiter plates at a final dilution of $1: 10$ (g tissue per ml buffer). The plates were incubated overnight at $4^{\circ} \mathrm{C}$ and then washed 3 times with phosphate-buffered saline containing tween (PBS-T). Anti-CMV (primary antibody) was added to the plates at a concentration of $1 \mathrm{fg} / \mathrm{ml}$ in PBS-T. The plates were incubated for $1.5 \mathrm{~h}$ at $37^{\circ} \mathrm{C}$ and washed 3 times with PBS-T. The goat anti-rabbit immunoglobulin conjugated to alkaline phosphatase was diluted 1:7500 in PBS-T and added to the plates. The plates were incubated at $37^{\circ} \mathrm{C}$ for 1 hour. The plates were washed in triplicate with PBS-T, the substrate (p-nitrophenylphosphate at $1 \mathrm{mg} / \mathrm{ml}$ in $10 \%$ diethanolamine, $\mathrm{pH} 9.8$ ) was added and the reactions were allowed to develop at room temperature. The absorbance values were read at $405 \mathrm{~nm}$ on Bio-RAD model 550-microplate reader (Bio-Rad Laboratories, Tokyo, Japan).

RT-PCR analysis. For the RNA analysis, the leaves were harvested at different times after inoculation and stored at $-80^{\circ} \mathrm{C}$ until further use. Total RNA was extracted following Suzuki et al. (2004) with some modifications. Briefly, leaves of randomly selected plants were ground in liquid nitrogen using a sterilised mortar and pestle and homogenised with the following extraction buffer: $100 \mathrm{mM}$ Tris$\mathrm{HCl}$ (pH 9.5), 10 mM EDTA (pH 8.0), 2\% lithium dodecyl sulphate, $0.6 \mathrm{M} \mathrm{NaCl}, 0.4 \mathrm{M}$ trisodium citrate and $5 \% 2$ mercaptoethanol. Following centrifugation at room temperature, the resulting aqueous phase was re-extracted with a chloroform/isoamyl alcohol (24:1) mixture. The supernatant was collected and extracted with water-saturated phenol, guanidium thiocyanate, sodium acetate ( $\mathrm{pH} 4.0$ ) and chloroform. The upper aqueous phase was precipitated with isopropanol. The precipitated RNA was collected, washed, airdried briefly and dissolved in RNase-free water. After treatment with RNase-free DNase, the DNase was inactivated according to the manufacturer's instructions (Takara Bio Inc., Shiga, Japan). Approximately $1 \mu \mathrm{g}$ of total RNA was reverse transcribed into single-stranded cDNA. An aliquot of the obtained cDNA was amplified by RT-PCR, as described by Suzuki et al. (2004), to monitor the expression of a set of well-characterised defense-related genes, such as $P R-1$ (Pieterse et al., 1998), PR-2, PR-5 (Oñate-Sánchez and Singh, 2002), PDF1.2, VSP (Penninckx et al., 1996) and Actin (Jones et al., 2003). The gene-specific primers used in these experiments are listed in Table 1.

Data analysis. The experiments were repeated at least thrice, and treatment means were separated using a Fisher's least significant difference (LSD) test for ELISA experiment and a Steel-Dwass test for disease severity experiment using Ekuseru-Toukei 2010 (Social Survey Research Infor- 
Table 1. Gene-specific primers used in RT-PCR analysis in this study

\begin{tabular}{cll}
\hline \hline Gene name & \multicolumn{1}{c}{ Forward primers $\left(5^{\prime}-3^{\prime}\right)$} & \multicolumn{1}{c}{ Reverse primers $\left(5^{\prime}-3^{\prime}\right)$} \\
\hline$P R-1$ & GTAGGTGCTCTTGTTCTTCC & TTCACATAATTCCCACGAGG \\
$P R-2$ & TCAAGGAAGGTTCAGGGATG & TCGGTGATCCATTCTTCACA \\
$P R-5$ & ATGGCAAATATCTCCAGTATTCACA & ATGTCGGGGCAAGCCGCGTTGAGG \\
$P D F 1.2 a$ & AATGAGCTCTCATGGCTAAGTTTGCTTCC & AATCCATGGAATACACACGATTTAGCACC \\
$V S P$ & TTTTACGCCAAAGGACTTGC & ATCCCGAGTTCCAAGAGGTT \\
$A C T I N$ & GTTGGGATGAACCAGAAGGA & GAACCACCGATCCAGACACT \\
\hline
\end{tabular}

mation CO., Ltd, Japan). All analyses were conducted at significance value of $\mathrm{P} 0.05$.

\section{Results}

Root colonisation. Our results show that SKT-1 was reisolated at high frequencies from Arabidopsis Col-0 plants at three weeks after planting. The re-isolation frequency was $95 \%$ (data not shown).

Effect of BGI of T. asperellum SKT-1 on systemic protection against CMV in $\boldsymbol{A}$. thaliana. CMV caused systemic mosaic and stunting symptom at 10 days post-inoculation (DPI) on Arabidopsis plants. Arabidopsis Col-0 plants grown in soils amended with BGI of SKT-1 exhibited reduction in CMV symptoms when compared with the untreated control plants. The disease severity of CMV was rated at 14 DPI. Arabidopsis Col-0, jar1, and ein3 plants treated with BGI of SKT-1 and the BTH treatment significantly reduced the disease severity rating when compared with the untreated control plants. However, no significant differences were observed between the Arabidopsis NahG and $n p r 1$ plants that were treated with BGI of SKT-1 and the control plants (Fig. 1).

CMV titre was detected in Arabidopsis plants by ELISA at 14 DPI. The CMV titre decreased significantly in Arabidopsis Col-0, jar 1, and ein3 plants treated with BGI of SKT1 , and the BTH treatment when compared to the control plants at 14 DPI. While the CMV titre was not reduced in the Arabidopsis NahG and nprl plants that were treated with SKT-1 at 14 DPI (Fig. 2).

Effect of CF of SKT-1 on systemic protection against CMV. Roots treatment with CF of SKT-1 1 day before the challenge inoculation with CMV significantly reduced disease severity in all Arabidopsis plants relative to the controls two weeks after virus inoculation (Fig. 3).

Similarly, ELISA demonstrated that CMV titre was significantly reduced in all Arabidopsis plants treated with CF of SKT-1 relative to the controls. However, the BTH treated npr 1 transgenic plants showed no significant differences in

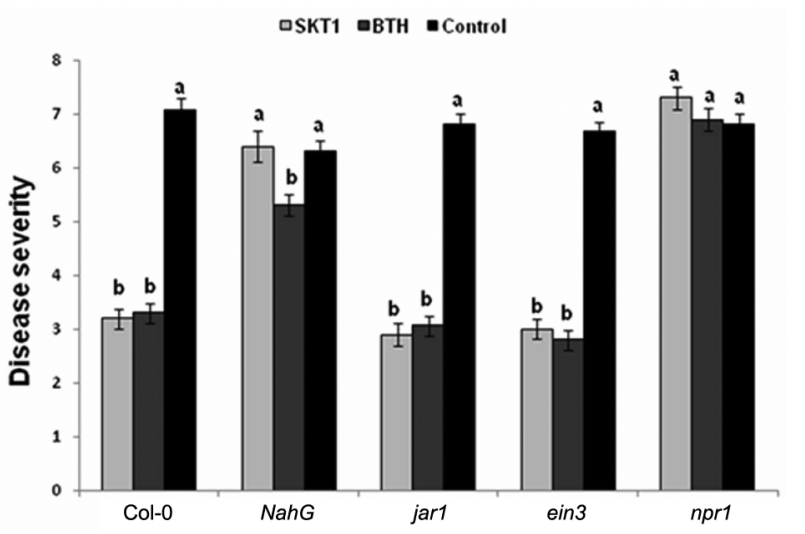

Fig. 1. Disease severity of Cucumber mosaic virus inoculated Arabidopsis thaliana lines treated with Trichoderma asperellum SKT-1 (as BGI) or BTH relative to non-treated control plants at 14 days post-inoculation. Columns represent mean values $(n=$ 10). Bars indicate standard errors. Different letters indicate significant difference by Steel-Dwass test at $\mathrm{P} \leq 0.05$.

Disease severity rating for Arabidopsis plants: 0; no symptoms; 2; mild deformation and mosaic of the youngest two leaves; 4; pronounced leaf deformation and mosaic of the youngest two leaves with progression of symptoms into sequentially older leaves; 6; pronounced leaf deformation and mosaic progressed beyond the two youngest leaves with all leaves expressing some form of cucumber mosaic virus -induced symptoms; 8; similar symptoms as described for a rating of 6 with plants also being stunted in growth (note that this stunting included both reduced internodes extension and smaller leaves); 10 ; plants were severely stunted with a majority of leaves being small, severely deformed and tightly bunched together (Ryu et al., 2004).

CMV titre compared with the control plants (Fig. 4).

Root colonization with SKT-1 stimulates systemic expression of SA-inducible plant defense genes. In order to learn more about the basis of resistance induced by BGI of SKT-1, we monitored the expression of a set of wellcharacterized defense related genes. The expression of these genes was systemically assessed in the leaves of Arabidopsis plants grown in soil with or without SKT-1 at $0,1,2,4$ and 6 days after challenge inoculation with CMV. Additionally, gene expression was assessed in the leaves of Arabidopsis plants treated with BTH as a positive control. 


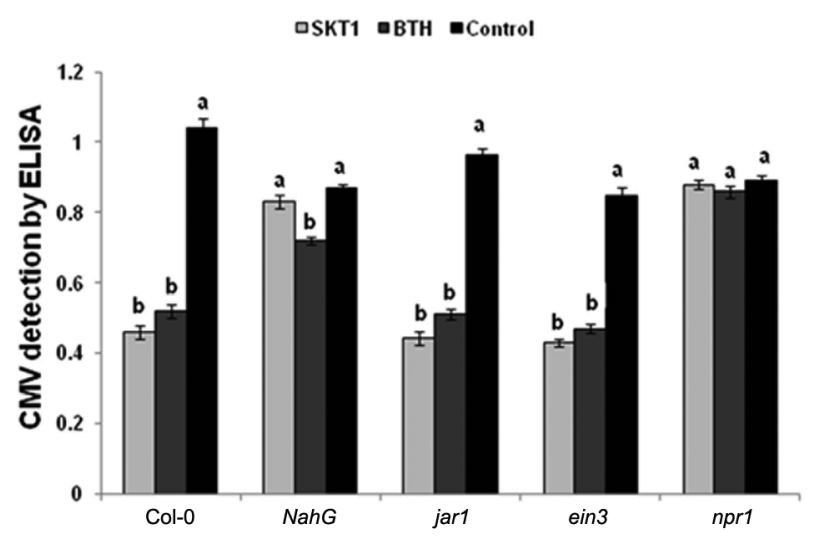

Fig. 2. Cucumber mosaic virus accumulation in leaves of Arabidopsis thaliana lines treated with either Trichoderma asperellum SKT-1 or BTH at 14 days post inoculation.

Columns represent mean values $(n=4)$. Bars indicate standard errors. Statistical comparisons are among treatments within the same line. The different letters indicate significant differences using Fisher's LSD at $\mathrm{P} \leq 0.05$.

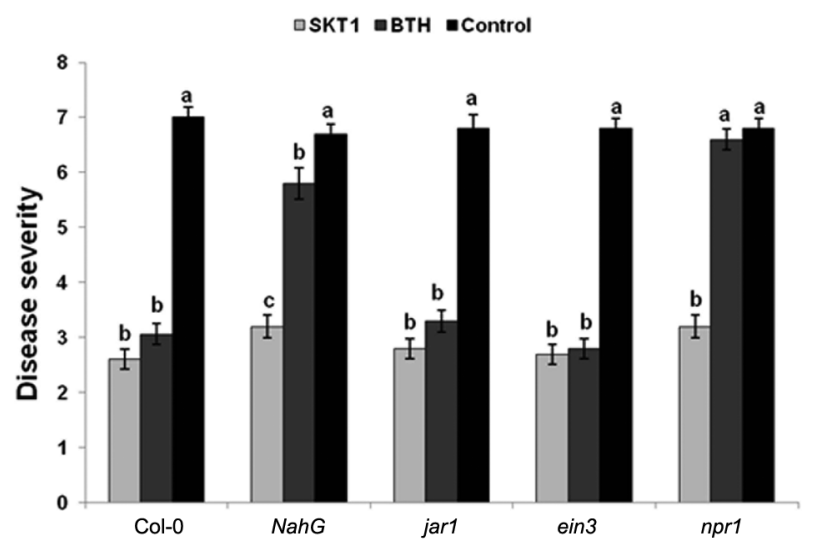

Fig. 3. Disease severity of Cucumber mosaic virus inoculated Arabidopsis thaliana lines treated with Trichoderma asperellum SKT-1 (as CF) or BTH relative to non-treated control plants at 14 days post-inoculation. Columns represent mean values $(n=10)$. Bars indicate standard errors. Different letters indicate significant difference by Steel-Dwass test for Arabidopsis at $\mathrm{P} \leq 0.05$.

Fig. 5 shows that SKT-1 significantly induced SA-inducible $P R-1, P R-2$ and $P R-5$ genes compared with non-treated control plants. In contrast, no significant induction of the JA/ET-inducible $P D F 1.2$ gene and JA-inducible $V S P$ gene was exhibited in the leaves of Arabidopsis plants treated with BGI of SKT-1 compared to control plants. Similarly, BTH treatment led to a large expression of SA-inducible genes, while no JA and ET-inducible gene expressions were elevated.

Treatment with CF of SKT-1 stimulates systemic expression of both SA and JA-/ET-inducible plant defense genes. Arabidopsis plants treated with CF of SKT-1 signifi-

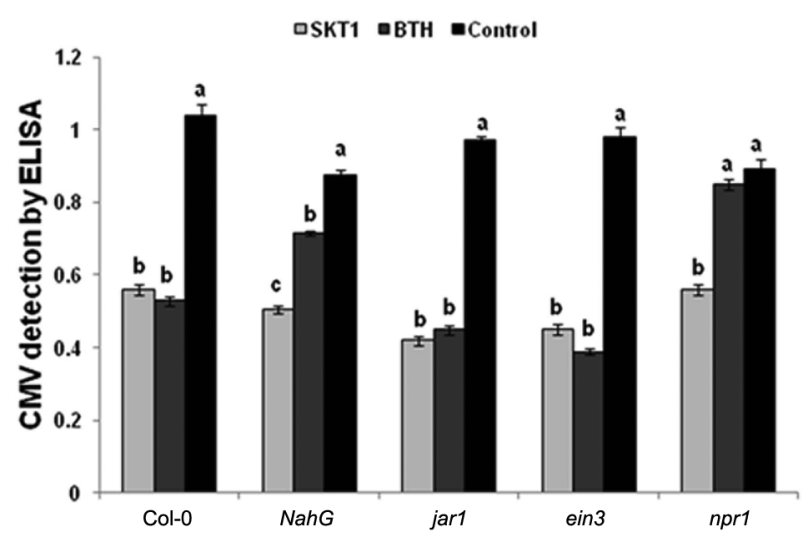

Fig. 4. Cucumber mosaic virus accumulation in leaves of Arabidopsis thaliana lines treated with either culture filtrate of Trichoderma asperellum SKT-1 or BTH at 14 days post inoculation. Columns represent mean values $(n=4)$. Bars indicate standard errors. Statistical comparisons are among treatments within inoculated or non-inoculated leaves and within the same line. The different letters indicate significant differences using Fisher's LSD at $\mathrm{P} \leq 0.05$.

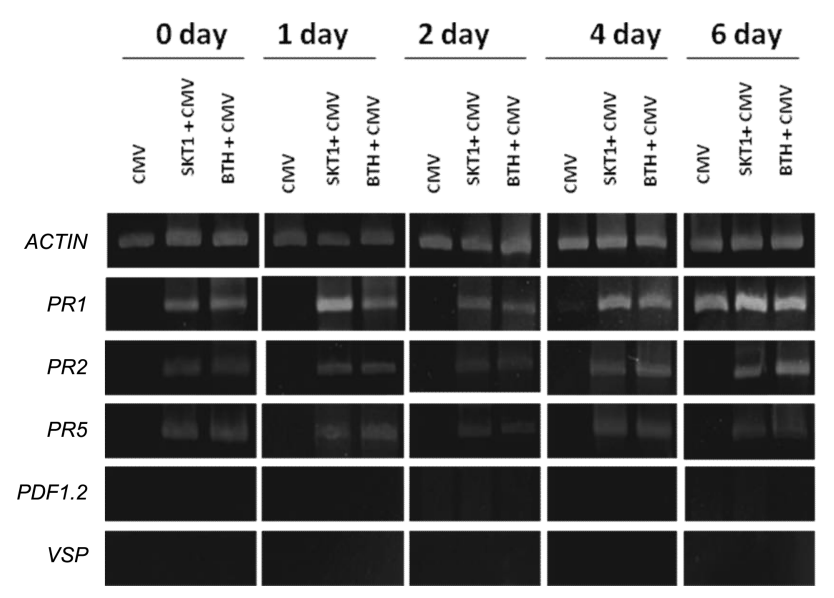

Fig. 5. Expression of defense-related genes in leaves of Arabidopsis Col-0 plants treated with Trichoderma asperellum SKT-1 or BTH $0.3 \mathrm{mM}$ (1 day before virus challenge inoculation) and inoculated with Cucumber mosaic virus at indicated time point. SA responsive $(P R-1, P R-2$ and $P R-5)$, ET-/JA-responsive $(P D F 1.2)$ and JA-responsive (VSP) were analyzed as representative marker genes by RT-PCR using specific primers for each gene. A constitutively expressed Actin was used as a control in RT-PCR.

cantly induced SA-inducible $P R-1, P R-2$, and $P R-5$ compared with control plants. Similarly, expression levels of JA and ET were elevated 1 day after CF treatment and continue elevated at 6 days after virus inoculation. In contrast, BTH treatment showed high expression levels of SAinducible $P R-1, P R-2$ and $P R-5$, while no induction of JAand/or ET-inducible genes was exhibited in Arabidopsis leaves compared with control plants (Fig. 6). 


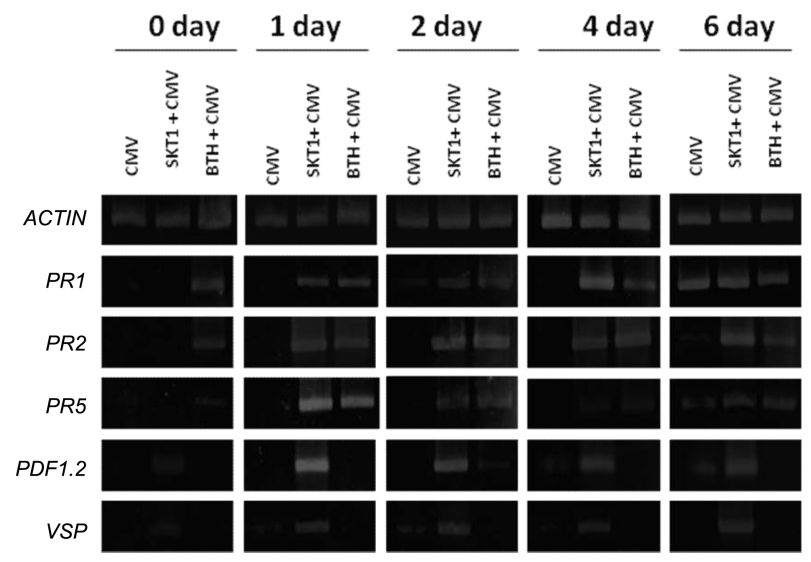

Fig. 6. Expression of defense-related genes in leaves of Arabidopsis Col-0 plants treated with $\mathrm{CF}$ of Trichoderma asperellum SKT-1 or BTH $5 \mathrm{mM}$ at 1day before virus challenge inoculation and inoculated with Cucumber mosaic virus at indicated time point. SA responsive ( $P R-1, P R-2$ and $P R-5)$, ET-/JA-responsive $(P D F 1.2)$ and JA-responsive (VSP) were analyzed as representative marker genes by RT-PCR using specific primers for each gene. A constitutively expressed Actin was used as a control in RT-PCR.

\section{Discussion}

Biocontrol fungi of the genus Trichoderma have developed an astonishing ability to interact, both parasitically and symbiotically, with different plants and microbes. These properties make these fungi ecologically very successful since strains have been found in agricultural, native prairie, forest, salt marsh and desert soils of all climatic zones (including tundra, Antarctic, and tropics), as well as in lake water, dead plant material, living roots of virtually any plant species, seeds, and air. Different species of Trichoderma including T. harzianum, T. viride (Govindasamy et al., 1989; Kovach et al., 2000), and T. atroviride (Hjeljord and Tronsmo, 2003) are effective biological control agents. Some of these have been commercialized under different trade names. Recently, T. asperellum SKT-1 has been found to act as effective biocontrol agent.

Disease suppression effect of SKT-1 was almost the same as chemical pesticides for the seedborne diseases of rice seedlings (Kumakura et al., 2003). SKT-1 has been successfully commercialized and is currently marketed as Ecohope, Eco-hope dry and Eco-hope DJ. Cucumber mosaic virus (CMV) is one of the most important viruses affecting production of field-grown vegetables worldwide (Tomlinson, 1987). CMV is particularly difficult to control because of its extremely broad natural host range and the ability to be transmitted in a nonpersistent manner by aphids (Palukaitis et al., 1992), so management options are limited. Thus, growers are in need of alternative management strategies, particularly those that are environmentally sound and easily implemented.

Induction of systemic resistance by beneficial microorganisms has been demonstrated in several plant species to combat diseases. Microbial-mediated induced systemic resistance (ISR) has been demonstrated against CMV (Ryu et al., 2004; Elsharkawy et al., 2012a, b). Several species of the genus Trichoderma added to the rhizosphere protect plants against broad range of plant pathogens, e.g., those that produce aerial infections, including viral, bacterial and fungal pathogens, which point to the induction of resistance mechanisms similar to the hypersensitive response (HR), SAR and ISR in plants (Harman et al., 2004). In recent years, increased attention has been paid to studying the direct interactions between Trichoderma spp. and plants, including molecular studies of plant defense mechanism elicitation (Woo et al., 2006; Contreras-cornejo et al., 2009). Research data accumulated in the past few years have produced a completely novel understanding of the way by which these fungi interact with plants. De Meyer et al. (1998) reported that bean root colonization by $T$. harzianum was effective in inducing defense responses. Additionally, penetration of $T$. asperellum in the root system triggered ISR in cucumber seedlings (Yedidia et al., 1999).

In this study, we demonstrated that BGI treatment of SKT-1 resulted in systemic protection against CMV in Col0 , jar 1 and ein3 but not in NahG and npr1. Moreover, RTPCR results showed increased expression levels of SAinducible genes, such as $P R-1, P R-2$ and $P R-5$, in the leaves of Arabidopsis plants treated by BGI of SKT-1 or BTH compared with expression of JA/ET-inducible genes. This suggests that the SA signaling pathway plays an important role in ISR in Arabidopsis by root colonisation with SKT-1. Mayers et al. (2005) found that SA-induced resistance to CMV resulted from inhibition of systemic virus movement in A. thaliana and tobacco, while in squash (Cucurbita реро) SA-induced resistance to CMV resulted from inhibited virus accumulation in directly inoculated tissue. Additionally, Trichoderma is able to trigger a long-lasting upregulation of SA gene markers in plants unchallenged by pathogens (Tucci et al., 2011).

On the other hand, in culture filtrate (CF) experiment disease severity was reduced in all Arabidopsis plants. Moreover, treatment with CF resulted in enhanced expression of SA-dependent PR genes as well as the JA/ET-inducible $P D F 1.2$ gene and JA-inducible VSP gene in the leaves of Arabidopsis plants. In contrast, BTH-induced SAR was accompanied by strong systemic induction of PR genes responsive to the SA pathway but not JA pathway. These results suggest that both the JA/ET signaling pathway and the SA signaling pathway combine in the signaling of ISR against CMV by CF of SKT-1 in A. thaliana. Recently, 
some reports showed the role of JA in induced resistance against CMV. For example, Ryu et al. (2004) showed that PGPR-mediated protection against CMV in A. thaliana was dependent on JA. Interestingly, colonization of Arabidopsis root by T. asperellum produces a clear ISR through an SA signaling cascade, and both the SA and JA/ET signaling pathways combine in the ISR triggered by cellfree culture filtrates of Trichoderma (Yoshioka et al., 2011). Additionally, culture filtrate of Penicillium simplicissmum GP17-2 induced systemic resistance against CMV following multiple defense pathway in Arabidopsis and tobacco (Elsharkawy et al., 2012a).

In conclusion, our results show that treatment with the BGI of SKT-1 induced systemic resistance against CMV through an SA signaling cascade. While, CF of SKT-1 elicited ISR against CMV via multiple pathways in Arabidopsis plants.

\section{Acknowledgments}

This work was supported by the Egyptian Government and a grant (KAKEN (B) 22380177) from the Japanese Ministry of Education, Culture, Sports, Science, and Technology (Monbukagakusho).

\section{References}

Beauchamp, C. J., Charest, M. H. and Gosselin, A. 2002. Examination of environmental quality of raw and composting deinking paper sludge. Chemosphere 46:887-895.

Beck, A. J., Johnson, D. L. and Jones, K. C. 1996. The form and bioavailability of non-ionic organic chemicals in sewage sludgeamended agricultural soils. Sci. Total Environ. 185: 125-149.

Bellamy, K. L., Chong, C. and Cline, R. A. 1995. Paper sludge utilization in agricultural and container nursery culture. $J$. Environ. Qual. 24:1074-1082.

Cao, H., Bowling, S. A., Gordon, A. S. and Dong, X. 1994. Characterization of an Arabidopsis mutant that is nonresponsive to inducers of systemic acquired resistance. Plant Cell 6:15831592.

Chao, Q., Rothenberg, M., Solano, R., Roman, G., Terzaghi, W. and Ecker, J. R. 1997. Activation of the ethylene gas response pathway in Arabidopsis by the nuclear protein ETHYLENEINSENSITIVE3 and related proteins. Cell 89:1133-1144.

Conejero, V., Picazo, I. and Segado, P. 1979. Citrus exocortis viroid (CEV): Protein alterations in different hosts following viroid infection. Virology 97:454-456.

Contreras-Cornejo, H. A., Macías-Rodríguez, L., Cortés-Penagos, C. and López-Bucio, J. 2009. Trichoderma virens, a plant beneficial fungus, enhances biomass production and promotes lateral root growth through an auxin-dependent mechanism in Arabidopsis. Plant Physiol. 149:1579-1592.

Conrath, U., Beckers, G. J., Flors, V., Garcia-Agustin, P., Jakab, G., Mauch, F. et al. 2006. Priming: getting ready for battle.
Mol. Plant-Microbe Interact. 19:1062-1071.

De Meyer, G., Bigirimana, J., Elad, Y. and Höfte, M. 1998. Induced systemic resistance in Trichoderma harzianum T39 biocontrol of Botrytis cinerea. Eur. J. Plant. Pathol. 104:279286.

Dubey, V. K., Aminuddin and Singh, V. P. 2010. Molecular characterization of Cucumber mosaic virus infecting Gladiolus, revealing its phylogeny distinct from the Indian isolate and alike the Fny strain of CMV. Virus Genes 41:126-134.

Durrant, W. E. and Dong, X. 2004. Systemic acquired resistance. Annu. Rev. Phytopathol. 42:185-209.

Elsharkawy, M. M., Shimizu, M., Takahashi, H. and Hyakumachi, M. 2012a. Induction of systemic resistance against Cucumber mosaic virus by Penicillium simplicissimum GP17-2 in Arabidopsis and tobacco. Plant Pathol. 61:964-976.

Elsharkawy, M. M., Shimizu, M., Takahashi, H. and Hyakumachi, M. 2012b. The plant growth-promoting fungus Fusarium equiseti and the arbuscular mycorrhizal fungus Glomus mosseae induce systemic resistance against Cucumber mosaic virus in cucumber plants. Plant Soil 361:397-409.

Fujiwara, T., Hirai, M. Y., Chino, M., Komeda, Y. and Naito, S. 1992. Effects of sulphur nutrition on expression of the soybean seed storage protein genes in transgenic petunia. Plant Physiol. 99:263-268.

Gianinazi, S., Ahl, P., Cornu, A., Scalla, R. and Cassini, R. 1980. First report of host P. protein appearance in response to fungal infection in tobacco. Physiol. Plant Pathol. 16:337-342.

Govindasamy, V. and Balasubramanian, R. 1989. Biological control of groundnut rust, Puccinia arachidis, by Trichoderma harzianum. J. Plant Dis. Prot. 96:337-345.

Harman, G. E., Howell, C. R. Viterbo, A., Chet, I. and Lorito. M. 2004. Trichoderma species-opportunistic, avirulent plant symbionts. Nature Rev. Microbiol. 2:43-56.

Heil, M. and Bostock, R. 2002. Induced systemic resistance (ISR) against pathogens in the context of induced plant defenses. Ann. Bot. 89:503-512.

Heiljord, L. G. and Tronsmo, A. 2003. Effect of germination initiation on competitive capacity of Trichoderma atroviride P1 conidia. Phytopathology 93:1593-1598.

Hoffmann, M. H. 2002. Biogeography of Arabidopsis thaliana (L.) Heynh. (Brassicaceae). J. Biogeogr. 29:125-134.

Hossain, M. M., Sultana, F., Kubota, M., Koyama, H. and Hyakumachi, M. 2007. The plant growth-promoting fungus Penicillium simplicissimum GP17-2 induces resistance in Arabidopsis thaliana by activation of multiple defense signals. Plant Cell Physiol. 48:1724-1736.

Jones, A. M., Ecker, J. R. and Chen, J.-G. 2003. A reevaluation of the role of the heterotrimeric $G$ protein in coupling light responses in Arabidopsis. Plant Physiol. 131:1623-1627.

Knoester, M., Pieterse, C. M. J., Bol, J. F. and van Loon, L. C. 1999. Systemic resistance in Arabidopsis induced by rhizobacteria requires ethylene-dependent signaling at the site of application. Mol. Plant-Microbe Interact. 12:720-727.

Koike, N., Hyakumachi, M., Kageyama, K., Tsuyumu, S. and Doke, N. 2001. Induction of systemic resistance in cucumber against several diseases by plant growth-promoting fungi: 
lignication and superoxide generation. Eur. J. Plant Pathol. 107: 523-533.

Kovach, J., Petzoldt, R. and Harman, G. E. 2000. Use of honey bees and bumble bees to disseminate Trichoderma harzianum 1295-22 to strawberry for Botrytis control. Biol. Control 18:235-242.

Kumakura, K.,Watanabe, S., Toyoshima, J., Makino, T., Iyozumi, H., Ichikawa, T., et al. 2003. Effectof Trichoderma sp. SKTlon suppression of sixdifferent seedborne diseases of rice. Jpn. J. Phytopathol. 69:384-392.

Lawton, K. A., Friedrich, L., Hunt, M., Weymann, K., Delaney, T., Kessmann, H., Staub, T. and Ryals, J. 1996. Benzothiadiazole induces disease resistance in Arabidopsis by activation of the systemic acquired resistance signal transduction pathway. Plant J. 10:71-82.

Lawton, K., Weymann, K., Friedrich, L., Vernooij, B., Uknes, S. and Ryals, J. 1995. Systemic acquired resistance in Arabidopsis requires salicylic acid but not ethylene. Mol. Plant-Microbe Interact. 8:863-870.

van Loon, L. C., Bakker, P. A. H. M. and Pieterse, C. M. J. 1998. Systemic acquired resistance induced by rhizosphere bacteria. Annu. Rev. Phytopathol. 36:453-483.

van Loon, L. C., Geraats, B. P. J. and Linthorst, H. J. M. 2006. Ethylene as a modulator of disease resistance in plants. Trends Plant Sci. 11:184-191.

Malamy, J., Carr, J. P., Klessig, D. F. and Raskin, I. 1990. Salicylic acid a likely endogenous signal in the resistance response of tobacco to viral infection. Science 250:1002-1004.

Mayers, C. N., Lee, K. C., Moore, C. A., Wong, S. M. and Carr, J. P. 2005. Salicylic acid-induced resistance to Cucumber mosaic virus in squash and Arabidopsis thaliana: contrasting mechanisms of induction and antiviral action. Mol. Plant-Microbe Interact. 18:428-434.

Metraux, J. P. and Boller, T. 1986. Local and systemic induction of chitinase in cucumber plants in response to viral, bacterial and fungal infections. Physiol. Mol. Plant Pathol. 28:161-169.

Meera, M. S., Shivanna, M. B., Kageyama, K. and Hyakumachi, M. 1994. Plant growth promoting fungi from zoysiagrass rhizosphere as potential inducers of systemic resistance in cucumbers. Phytopathology 84:1399-1406.

Meera, M. S., Shivanna, M. B., Kageyama, K. and Hyakumachi, M. 1995. Persistence of induced systemic resistance in cucumber in relation to root colonization by plant growth promoting fungal isolates. Crop Prot. 14:123-130.

Oñate-Sánchez, L. and Singh, B. K. 2002. Identification of Arabidopsis ethylene-responsive element binding factors with distinct induction kinetics after pathogen infection. Plant Physiol. 128:1313-1322.

Palukaitis, P. and García-Arenal, F. 2003. Cucumoviruses. $A d v$. Virus Res. 62:242-323.

Palukaitis, P., Roossinck, M. J., Dietzgen, R. G. and Francki, F. I. B. 1992. Cucumber mosaic virus. Adv. Virus Res. 41:281-348.

Penninckx, I. A. M. A., Eggermont, K., Terras, F. R. G., Thomma, B. P. H. J., De Samblanx, G. W., Buchala, A., Métraux, J.-P., Manners, J. M. and Broekaert, W. F. 1996. Pathogen-induced systemic activation of a plant defensin gene in Arabidopsis follows a salicylic acid-independent pathway. Plant Cell 8:2309-2323.

Pieterse, C. M. J., van Wees, S. C. M., Hoffland, E., van Pelt, J. A. and van Loon, L. C. 1996. Systemic resistance in Arabidopsis induced by biocontrol bacteria is independent of salicylic acid accumulation and pathogenesis-related gene expression. Plant Cell 8:1225-1237.

Pieterse, C. M. J., van Wees, S. C. M., van Pelt, J. A., Knoester, M. L. R., Gerrits, H., Weisbeek, P. J. and van Loon, L. C. 1998. A novel signaling pathway controlling induced systemic resistance in Arabidopsis. Plant Cell 10:1571-1580.

Robert-Seilaniantz, A., Navarro, L., Bari, R. and Jones, J. D. 2007. Pathological hormone imbalances. Curr. Opin. Plant Biol. 10:372-379.

Ryals, J., Neuenschwander, U., Willits, M., Molina, A., Steiner, H. Y. and Hunt, M. 1996. Systemic acquired resistance. Plant Cell 8:1809-1819.

Ryu, C.-M., Murphy, J. F., Mysore, K. S. and Kloepper, J. W., 2004. Plant growth-promoting rhizobacteria systemically protect Arabidopsis thaliana against Cucumber mosaic virus by a salicylic acid and NPR1-independent and jasmonic aciddependent signaling pathway. Plant J. 39:381-392.

Staswick, P. E., Su, W. and Howell, H. 1992. Methyl jasmonate inhibition of root growth and induction of a leaf protein are decreased in an Arabidopsis thaliana mutant. Proc. Natl. Acad. Sci. USA 89:6837-6840.

Suzuki, Y., Kawazu, T. and Koyama, H. 2004. RNA isolation from siliques, dry seeds and other tissues of Arabidopsis thaliana. Biotechniques 37:542-544.

Tomlinson, J. A. 1987. Epidemiology and control of virus diseases of vegetables. Ann. Appl. Biol. 110:661-681.

Tucci, M., Ruocco, M., De Masi, L., De Palma, M. and Lorito, M. 2011. The beneficial effect of Trichoderma spp. on tomato is modulated by the plant genotype. Mol. Plant Pathol. 12:341354.

Woo, S. L., Scala, F., Ruocco, M. and Lorito, M. 2006. The molecular biology of the interactions between Trichoderma spp., phytopathogenic fungi, and plants. Phytopathology 96: 181-185.

Yan, Z., Reddy, M. S., Ryu, C. M., McInroy, J. A., Wilson, M. and Kloepper, J. W. 2002. Induced systemic protection against tomato late blight elicited by plant growth-promoting rhizobacteria. Phytopathology 92:1329-1333.

Yedidia, I., Benhamou, N. and Chet, I. 1999. Induction of defense responses in cucumber plants (Cucumis sativus L.) by the biocontrol agent Trichoderma harzianum. Appl. Environ. Microbiol. 65:1061-1070.

Yoshioka, Y., Ichikawa, H., Naznin, H. A., Kogure, A. and Hyakumachi, M. 2011. Systemic resistance induced in Arabidopsis thaliana by Trichoderma asperellum SKT-1, a microbial pesticide of seedborne diseases of rice. Pest Manag. Sci. 68:60-6 http://dx.doi.org/10.1002/ps.2220

Zehnder, G. W., Yao, C., Murphy, J. F., Sikora, E. R. and Kloepper, J. W. 2000. Induction of resistance in tomato against Cucumber mosaic cucumovirus by plant growth promoting rhizobacteria. BioControl 45:127-137. 